\title{
Bibliotecas públicas e telecentros: ambientes democráticos e alternativos para a inclusão social
}

\author{
Angela Maria Barreto \\ Professora doutora do Instituto de Ciência da Informação da UFBA. \\ E-mail:ambar@ufba.br \\ Maria Dulce Paradella \\ Mestranda do Programa de Pós-graduação do Instituto de Ciência da \\ Informação (ICI) da Universidade da Bahia (UFBA). \\ E-mail: dulce@attglobal.net \\ Sônia Assis \\ Auxiliar de biblioteca na Faculdade de Direito da UFBA e formanda em \\ bBiblioteconomia e documentação no ICI/UFBA. \\ E-mail: massaserena@yahoo.com.br
}

\begin{abstract}
Resumo
0 acesso e 0 uso da informação são questões relacionadas ao desenvolvimento humano em seus múltiplos aspectos. Percebe-se um diferencial entre as pessoas que têm acessibilidade aos meios de informação - uma pequena parcela da população - e as que não têm. Nesse sentido, as bibliotecas públicas, os telecentros ou, ainda, a articulação entre os dois organismos de informação são propostos com o objetivo de democratizar 0 acesso e 0 uso da informação junto às comunidades e segmentos sociais alijados da participação em sociedade. Essa é a reflexão, feita a partir da literatura e documentos sobre o objeto deste texto, com ênfase nos telecentros, visto que as bibliotecas públicas, historicamente, vêm sendo debatidas há muito tempo, enquanto que os telecentros são organismos emergentes e devem contar com políticas mais sólidas, para que não esbarrem nos mesmos entraves que impossibilitaram 0 sucesso daquelas. Iniciativas de comunidades, em particular, têm oferecido resultados otimistas nesse sentido.
\end{abstract}

\section{Palavras-chave}

Biblioteca pública. Telecentro. Tecnologia de informação e comunicação. Inclusão social.

\section{Public libraries and the telecenters: information organisms to democratize and social inclusion}

\begin{abstract}
Both the access and the use of information are issues related to human development in its multiple aspects. There is a difference which can be noticed between people who have access to the means of information - a small percentage of the population - and those who do not. This way, the public libraries, the telecenters or still the articulation between these two information organisms are proposed with the objective to democratize the access and the use of information within communities and social segments which are currently excluded from participating in society. This is the reflection proposed, based on literature and documents on the object of this text, with emphasis on the telecenters, once the public libraries have been historically debated since long ago, whereas the telecenters are emergent organisms and should count with more solid policies not to come up against the same restraints which have impeded the success of the former. The initiatives of some communities, in particular, have provided optimistic results in this direction.
\end{abstract}

\section{Keywords}

Public Library. Telecenter. Information and communication technology. Social inclusion.

\section{INTRODUÇÃO}

A trajetória histórica aponta diversas relações entre o sujeito e a informação, desde a informação genética e os órgãos dos sentidos - que ocorrem a partir de uma interação natural, biológica, e que nos propiciam o contato com o mundo externo - até as formas de representações simbólicas. Nesse trâmite, linguagem e pensamento entrecruzam-se no uso e no acesso à informação e na construção do conhecimento; são articulantes ao cognitivo. Marcam e definem a sociedade humana, como um fazer contínuo e um trabalho que se transforma a cada momento. No cerne da questão, a comunicação dialógica do pensamento que se transforma e que, ao mesmo tempo, é transformador, criativo.

Na Idade Moderna - época de grandes transformações científicas e culturais -, a imprensa industrial traz grande expectativa em relação ao novo sentido da informação a partir da circulação do impresso, percebido como forma especial de democratização e, por isso, de participação social.

Nesse momento, as bibliotecas públicas são compreendidas como organismos de vital importância social na circulação da informação, e as políticas públicas começaram a surgir e a fundamentar ações nesse contexto. Atualmente, o aparecimento das tecnologias da informação acelera o processamento, o armazenamento e a comunicação da informação, e um novo cenário de otimismo parece evocar a euforia da inclusão social, isto é, a participação social de todos os sujeitos, independentemente de classe social, raça ou credo. Assim, as Tecnologias de Informação e Comunicação (TICs) consolidam-se como importante estratégia para o desenvolvimento educacional, econômico, político e cultural de uma sociedade.

O Manifesto da Unesco (1994) sobre a biblioteca pública aponta para a necessidade de igualdade de acesso à informação a todos os cidadãos, independentemente de idade, raça, sexo, religião, nacionalidade, língua ou condição social. Nesse aspecto, o que fundamenta a existência de uma biblioteca pública, além da guarda da memória, é a disseminação do conteúdo do seu acervo, o que redunda em um processo social inclusivo, pelo acesso, uso e democratização da informação, científica e cultural, além das informações úteis e necessárias 
à atuação do cidadão no dia-a-dia. Vê-se a biblioteca pública como promotora da igualdade social, pela oferta de oportunidades a todos, e como força viva para a educação, cultura e informação. Entre os enunciados do Manifesto da Unesco, inserem-se dois propósitos que nos chamam a atenção por já serem focados nas novas tecnologias:

- garantir aos cidadãos todo tipo de informação comunitária;

- facilitar o desenvolvimento da informação e da habilidade de uso de tecnologias.

A criação dos Telecentros visa, igualmente, a esses propósitos, permitindo amplo acesso à informação pelas camadas sociais mais desfavorecidas. Segundo o Livro Verde da Sociedade da Informação no Brasil (TAKAHASHI, 2000), documento que esboça diretrizes para a inserção do Brasil na sociedade da informação, o país aponta para a necessidade da inclusão social, via educação e promoção do acesso à informação. Vincula essas condições ao exercício da cidadania e da promoção social. O seu capítulo 4, Educação na Sociedade da Informação, inicia-se:

A educação é o elemento-chave na construção de uma sociedade baseada na informação, no conhecimento e no aprendizado. Parte considerável do desnível entre indivíduos, organizações, regiões e países deve-se à desigualdade de oportunidades relativas ao desenvolvimento da capacidade de aprender e concretizar inovações. Por outro lado, educar em uma sociedade da informação significa muito mais que treinar as pessoas para o uso das tecnologias de informação e comunicação: trata-se de investir na criação de competências suficientemente amplas que lhes permitam ter uma atuação efetiva na produção de bens e serviços, tomar decisões fundamentadas no conhecimento, operar com fluência os novos meios e ferramentas em seu trabalho, bem como aplicar criativamente as novas mídias, seja em usos simples e rotineiros, seja em aplicações mais sofisticadas. Trata-se também de formar os indivíduos para "aprender a aprender", de modo a serem capazes de lidar positivamente com a contínua e acelerada transformação da base tecnológica.

Percebe-se um consenso: o de que a consolidação da democracia depende de um sistema educacional forte e satisfatório, o que pressupõe o acesso à cultura e à informação, questões que se imbricam. Originários de datas diferentes, os dois documentos mostram as bibliotecas públicas e os telecentros como organismos inclusivos e até complementares. Possuem objetivos comuns, reconhecendo a informação como questão fundamental para a cidadania, para a formação de sujeitos conscientes de seus deveres e direitos. É nesse sentido que o acesso e o uso da informação se referem à importante estratégia para o desenvolvimento educacional, econômico, político e cultural de uma sociedade.
Nos países em desenvolvimento, em especial no Brasil, percebese um diferencial entre as pessoas que têm acessibilidade aos meios de informação - uma pequena parcela da população - e as que não têm. Essa questão é importante para muitos segmentos sociais e conscientiza a sociedade da premente necessidade de reverter a situação.

Na sociedade atual, a informação é vista como necessidade fundamental e com propósitos não necessariamente iguais. A administração de organizações a enxerga como capital intangivel; os setores governantes, como forma de controlar ou democratizar a sociedade. Segundo Ferreira, Spence e Straubhaar (JAMBEIRO; SILVA; BORGES, 2007, p.237-257), a informação assume finalidades específicas para diferentes atores sociais: "para a sociedade civil, o acesso à informação tem como propósito desenvolver o potencial criativo e intelectual [...] e, de modo geral, permitir o exercício da cidadania."

As bibliotecas públicas e os telecentros são dois organismos de informação inseridos nesse propósito, capazes de democratizar o acesso e o uso da informação junto a comunidades e segmentos sociais alijados da efetiva participação em sociedade, articulando-se com a escola e seus laboratórios.

É este o objetivo deste artigo: refletir sobre o papel desses espaços informacionais, organismos pluralistas, agentes da inclusão sociocultural. Os telecentros - ambientes emergentes - merecem muita atenção para se consolidarem como espaços de inclusão e não repetirem a mesma trajetória das bibliotecas públicas, que são precárias, não só em quantidade, mas também na qualidade dos acervos e dos serviços prestados (BARRETO, 2006, p.167). As bibliotecas públicas - como espaço público de uso e acesso à informação -, desde há muito, estão na pauta das discussões em nosso país, o que indica reversão nesse quadro social brasileiro.

\section{BIBLIOTECAS PÚBLICAS}

Historicamente, as bibliotecas tiveram diferentes concepções. Cada uma refletia o tipo de sociedade de determinada época, com um discurso de incentivo, ou não, à leitura e ao acesso à informação. Até o início do século XIX, o modelo de biblioteca atendia à idéia de arquivo-museu, lugar de memória e depósito do patrimônio bibliográfico. Esse modelo viera a ser substituído por outro, a partir da segunda metade do século, que acreditava no efeito moralizador e educativo dos textos de leitura sobre a população. Após a segunda metade do século $\mathrm{XX}$, a biblioteca passou a ser considerada um centro cultural e de informação, inclusive sendo ao seu acervo anexados os novos suportes informacionais - vídeos, discos, jornais etc. - e posteriormente as TICs. Como centro de cultura, suas atividades priorizam apresentações musicais, exposições, debates etc. Posteriormente, começa a idéia de uma biblioteca voltada à comunidade e para seu acesso à informação. 
Evidentemente, a trajetória foi arregimentada por diferentes discursos e posicionamentos. No primeiro momento, o discurso era erudito e conservador, de índole restritiva por razões acadêmicas e morais, tem certas semelhanças com o tradicional discurso, igualmente restritivo, ainda que por outras causas, do mundo eclesiástico. O segundo, reformista e moralizador, unido ao desenvolvimento por idênticas razões de escolarização, concebia a leitura como um bem em si mesmo. Um bem, de qualquer modo, controlado e dirigido à moralização da classe operária: um remédio, da mesma forma que a escola, diante da questão social que concebia a biblioteca como o santuário da leitura para todos. O terceiro fazia da leitura uma atividade cultural a mais, juntamente com outras, como as exposições, as audições musicais, as conversas ou conferências e as projeções, com as quais vinha a concordar no espaço e no tempo. O quarto, sem deixar totalmente de lado os anteriores, torna a biblioteca um lugar de busca e acesso à informação (FRAGO, op.cit., p.28).

O advento das tecnologias da comunicação e informação deu pulso à expansão de conceitos de biblioteca, ampliandoos além do da biblioteca tradicional. Biblioteca eletrônica, ciberteca, biblioteca virtual, biblioteca de realidade virtual e biblioteca digital são nomes diferentes que se confundem, são definições que se sobrepõem. São modelos para a nova etapa da evolução das bibliotecas (AQUINO, 2004, p.7-14).

Marchiori (1997, p.117) vai estabelecer algumas dimensões das novas bibliotecas, vistas sob a ótica das TCIs, e que as diferenciam:

- polimídia - refere-se às bibliotecas com acervos formados a partir de diferentes meios de suportes da informação. São as bibliotecas que se utilizam de "extensa e variada gama de mídias". O computador pode estar disponível para o usuário, mas não é utilizado para a automação do acervo;

- eletrônica - utiliza-se do computador para os processos básicos da biblioteca: armazenagem, recuperação e disponibilidade da informação;

- digital - as informações nelas contidas existem na forma digital, em diferentes meios físicos distintos do papel: discos magnéticos, discos óticos, imagem, áudio etc. Não contém livros ou revistas na forma convencional, e a informação pode ser acessada em locais específicos e remotamente;

c virtual - está relacionada "com o conceito de acesso por meio de redes a recursos de informação disponíveis em sistemas de base computadorizada, normalmente remotos", portanto precisam da existência de uma rede de comunicação eletrônica. Apresenta-se como "alternativa para ampliar as condições de busca, disponibilidade e recuperação de informação de maneira globalizada, qualitativa, pertinente e racional" (MARCHIORI, op. cit., p.114).
A autora fala, ainda, de uma diferenciação entre biblioteca virtual e biblioteca de realidade virtual, cuja "essência apresenta uma aplicação de programas de computador para simular estruturas físicas de bibliotecas". Os conceitos usados para a nova biblioteca imbricam-se e chocam-se, podendo conter vários aspectos uns dos outros. As bibliotecas atuais podem ser entendidas de formas diferentes e variadas, que vão do acesso remoto aos conteúdos informacionais virtuais, até a possibilidade de combinação de materiais físicos eletrônicos e impressos.

O que se pode dizer é que, cada vez mais, "a informação torna-se cada vez menos ligada ao objeto físico que a contém" (LEVACOV, 1997), o que redunda em diferente noção de biblioteca: as "bibliotecas sem paredes para livros sem páginas".

Com maior ênfase, esse é um momento em que as bibliotecas são vistas como possibilidades de exercício da cidadania a favorecer a construção de uma sociedade inclusiva. No Brasil, sem o devido respaldo para a implantação efetiva de políticas, as bibliotecas públicas refletem os mesmos problemas, as mesmas deficiências apontadas para o sistema de ensino brasileiro, apesar das inúmeras propostas para desenvolvê-las e dos ideais de muitos que empreenderam esforços para sua consolidação. Com relação às bibliotecas públicas, a Fundação Instituto Brasileiro de Geografia e Estatística (IBGE) apontou, em 1999, 19\% das 5.506 cidades brasileiras que as possuem. Mas não só a quantidade, a qualidade é a questão fundamental, a oferta de serviços possibilitada por sua infra-estrutura. No entanto, o consenso permanece:

a biblioteca é uma tentativa de inclusão social que se configura como ambiente democrático independente da condição social, pois a informação exerce papel fundamental no grau de consciência que cada cidadão tem dos seus direitos e deveres como membros de uma sociedade (PIMENTEL, 2006, p.22).

\section{Suaiden (1980) reforça o pensamento acima:}

[...] à medida que a biblioteca pública se vincular adequadamente com a comunidade, ela passará a ser o caminho que possibilitará a participação efetiva na sociedade da informação. Isso é de extraordinária importância em um país onde a desinformação atinge altas proporções, e, sem essa oportunidade, milhares de pessoas jamais terão oportunidades de entender e de ter noção dos seus direitos e deveres em uma sociedade globalizada, pois o acesso à informação, nos novos tempos, significa o investimento adequado para diminuir as desigualdades sociais e as formas de dominação que foram dominantes na história contemporânea.

Ainda que elitista na freqüência, as bibliotecas públicas brasileiras começam a despontar no século XIX, sendo a primeira, uma iniciativa de cidadãos, coordenada por um senhor de engenho, em Salvador, na Baía de Todos os Santos, 
em 1811. A Biblioteca Real, trazida de Portugal por D. João VI, só foi aberta ao público em 1814. A partir daí, outras bibliotecas foram criadas por iniciativas governamentais, ainda nesse século, e praticamente todas experimentaram dificuldades, das mais variadas. Na Primeira República, foram criadas muitas bibliotecas públicas, mas pode-se dizer que foi à época getuliana que elas começam a apresentar um contorno de funcionamento e serviços. O Instituto Nacional do Livro (INL), criado em 1937, alavancou contribuições expressivas ao desenvolvimento das bibliotecas públicas.

A incorporação das bibliotecas públicas à agenda governamental está entre essas contribuições, o que implica inclusão de verba específica para sua manutenção, no orçamento público. Outra ação de promoção e coletivização de textos e outros materiais são os programas de carros-biblioteca e caixas-estante. Em 1961, o Decreto Lei 51223 criou o Serviço Nacional de Bibliotecas, incentivando a criação de bibliotecas públicas, mas os objetivos não foram cumpridos e, em 1968, outro Decreto Lei, o de número 62239, incorporou o Serviço Nacional de Bibliotecas ao INL.

Com a reforma do ensino em 1971, houve grande incremento das bibliotecas públicas brasileiras. Com a falta de bibliotecas escolares, os alunos delas se utilizavam, e ainda se utilizam, para suas pesquisas, das bibliotecas públicas existentes, provocando, assim, a escolarização das mesmas, que passaram a dar prioridade ao atendimento estudantil em detrimento de outros segmentos da comunidade, para os quais deveriam prestar serviços, de acordo com sua missão, sacramentada pelo Manifesto da Unesco. O Projeto Escola Parque, criado por Anísio Teixeira, destaca-se por estabelecer vínculos entre biblioteca e sala de aula ( SOUSA, 2007, 256f).

Momento importante para as bibliotecas públicas brasileiras, que se configura como um marco ao seu desenvolvimento, foi a criação do Sistema Nacional de Bibliotecas Públicas, em 1977, que em muito melhorou suas condições. Até então, o Sistema Nacional de Bibliotecas Públicas era coordenado pelo INL; mas, em 1999, passou para a Fundação Biblioteca Nacional.

A partir desse momento, aparecem outras iniciativas e políticas voltadas ao incentivo da leitura que, necessariamente, passam pela missão das bibliotecas públicas, mas não conseguem efetividade, por sofrerem descontinuidade, provocada por interesses políticos diversos e mais as contingências sociais.

Destacam-se iniciativas no âmbito educacional em algumas escolas, mormente as de ensino privado, com a oferta de palestras e cursos, mas não uma disciplina específica que a nosso ver seria complementadora e orientadora ao acesso às fontes de informação e ao uso de bibliotecas. Está se falando de uma das vertentes dos estudos de usuários que se intensificaram na década de 80 , por força do entendimento de que as bibliotecas, como unidades de informação, deveriam fundamentar-se em princípios da ciência da administração. Estudar o perfil dos usuários, para adequar o acervo, constitui economia substancial; e mais: oferecer um "treinamento", uma orientação ao usuário, possibilita a autonomia no uso da biblioteca e passa a se constituir em ação importante, apesar de pensamentos resistentes que privilegiavam os cuidados físicos para com o objeto livro.

As facilidades trazidas pelas tecnologias informacionais, de um modo geral, aumentaram as possibilidades de obter informações atuais, o que favorece os serviços prestados pelas bibliotecas públicas. Porém, essas facilidades são subutilizadas pelos usuários, seja em decorrência da falta de orientação; do desconhecimento do suporte eletrônico; da falta de estímulo, por não haver um programa que divulgue os serviços e atividades desenvolvidas pelas bibliotecas e demais fontes de informações disponíveis; da falta de acesso; da resistência das pessoas ao novo representado pelas tecnologias; da falta de cultura informacional; de deficiências financeiras das bibliotecas para implantar os serviços tecnológicos etc. Além disso, o provável déficit de tecnologia com teleinformática nas bibliotecas provoca dificuldades de ordem sociais, econômicas, informacionais, gerenciais, psicológicas e profissionais.

Somente quando um governo encarar de forma prioritária a importância da educação e da informação para o desenvolvimento do país é que os ambientes informacionais, tais como as bibliotecas públicas, telecentros, laboratórios, escolas e espaços culturais, poderão constituir-se em espaços de democratização e inclusão social.

Lamentavelmente, o que se pode dizer é que as bibliotecas públicas brasileiras, em sua maioria decadentes, expressam a falta de planejamento e de competência dos governantes e da sociedade como um todo. Dar a elas a devida estrutura não é só papel dos governantes; passa também pela formação de espírito crítico por parte da comunidade, que deve exigir serviços e responsabilizar-se por eles. A ausência de espírito crítico é oriunda da falta de acesso e uso da informação, e, assim, o ciclo é vicioso e permanece.

Com o advento da sociedade da informação, à biblioteca pública foi dada uma nova missão: a de contribuir para a inclusão digital. É um novo salto civilizatório brasileiro, que é dado, mais uma vez, sem as devidas providências em relação à infra-estrutura, recursos e, principalmente, educação, o que permitiria a formação de habilidades e competências para usar e acessar informações, independentemente de seus suportes. A educação articula-se com a inclusão digital, sem nenhuma dúvida, pois, quando se fala de inclusão digital, não se está referindo apenas ao uso dos computadores, mas também à competência necessária para localizar, ler, compreender, analisar e escolher as informações, o que exige certa sistematização, criatividade e criticidade por parte do 
indivíduo. Pimentel (2006, p.43) afirma que "é indiscutível que a questão da educação é fundamental para os tempos digitais e que a inclusão digital está relacionada com o nível educacional do indivíduo".

Do ponto de vista da inclusão social na sociedade da informação, as bibliotecas públicas podem dar decisiva contribuição, estando ela em posição privilegiada, tornando a informação e a cultura acessíveis a todos, independentemente de suas possibilidades financeiras e de suas capacidades. No entanto, essa é tarefa complexa, que depende das exigências da sociedade e dos esforços políticos em torná-las realidade.

Na sociedade da informação, vê-se esboçar um novo ambiente informacional para democratizar o acesso e o uso à informação e que, se não contar com políticas efetivas, em parcerias ou não com ONGs, universidades, empresas estatais e privadas, incorrerá nos mesmos impasses que dificultaram o sucesso das bibliotecas públicas brasileiras. Para que isso não aconteça, propõe-se um trabalho integrado aos outros ambientes informacionais, aqui já elencados: os telecentros.

\section{TELECENTROS}

Entende-se por telecentro um espaço público para acesso e uso da informação através das TICs, com a finalidade de capacitar comunidades, reduzir desigualdades econômicas e sociais e promover a cidadania. Segundo Paradella (2008, p 96), a Unesco define telecentros como sendo

[...] plataformas pertencentes às comunidades que fornecem uma base variada de serviços em informação e informática para fins comerciais e de desenvolvimento baseadas nos conceitos de biblioteca comunitária e centro comunitário de aprendizagem [...]

A criação de telecentros já é considerada um fenômeno internacional (O'NEIL, 2002). Eles estão, praticamente, em todo mundo: desde os países mais ricos, até os mais pobres. A primeira referência sobre telecentros na literatura internacional surgiu em 1974, quando o termo "escritório satélite" foi usado na Califórnia para atender aos empregados de uma companhia que residiam em locais distantes do escritório central (OBRA AGUILA; CÂMARA; MELENDES, 2003, p.396). Nos países nórdicos, mais especificamente, na Suécia e na Dinamarca, os primeiros telecentros surgiram em 1985, com a denominação de telecottages.

O êxito das experiências na Suécia e Dinamarca fez com que vários países reproduzissem a iniciativa, inclusive o modelo está sendo adotado em quase toda a América Latina, Ásia e África (INFOTICS,2004). Nos Estados Unidos, o Playing2Win (P2W), nascido na década de 80, no bairro do Harlem, em Nova York, foi o primeiro centro comunitário de tecnologia (CCT).
O acesso e o uso da informação por intermédio das tecnologias de informação e comunicação são considerados, por governos e sociedades, como estratégias para a capacitação de comunidades, visando à redução de desigualdades econômicas e sociais, principalmente em países menos desenvolvidos. Sabemos que existe uma correlação entre o acesso à informação, a adoção das tecnologias de informação e comunicação e o desenvolvimento econômico e social (CAMPAL, 2004, p.1).

A difusão de acesso às redes de informação no mundo é bastante desigual. No caso dos países em desenvolvimento, em especial no Brasil, o uso de alternativas de compartilhamento de recursos constitui estratégia de suma importância para ampliar o acesso aos serviços da rede, uma vez que se considere a limitação de ordem econômica da maioria da população (TAKAHASHI, 2000, p.34).

Dessa forma, o telecentro, ou uma de suas várias denominações, surge como uma solução de menor custo para viabilizar o acesso e o uso da informação em comunidades de menor poder aquisitivo. As denominações surgidas para telecentros, encontradas na literatura nacional e internacional, baseiamse em critérios como finalidade, estrutura física e forma de sustentação. O que é comum nelas é que o telecentro tem o propósito de dinamizar comunidades locais e proporcionar as informações necessárias para seu desenvolvimento educacional, pessoal, social e econômico (GÓMEZ; HUNT; LAMOUREUX, 1999).

Os telecentros propõem-se a ser algo mais que simples centros provedores de tecnologia; também são centros comunitários culturais, lugares de encontro e pontos de informação para o cidadão.

De modo geral, os objetivos dos telecentros vão além. O que se propõe é facilitar a criação de sistemas de informação para a comunidade, o acesso às informações locais e globais de interesse dos cidadãos e à internet. Trata-se de um local de alfabetização digital, de interlocução direta da comunidade. Espera-se, por meio de suas ações, oferecer serviços à comunidade, como o portal do cidadão, serviços para empresas, bolsas de emprego, anúncios da comunidade local etc. O que se espera com isso é diminuir o vão entre os "ricos-informados" e os "pobres-desinformados".

Para que esses objetivos sejam alcançados, Afonso (2000, p.10) propõe a devida atenção à:

infra-estrutura de acesso - facilidades coletivas e individuais de acesso local;

- capacitação - treinamento no uso do meio e formação de quadros para configurar, operar e desenvolver serviços e sistemas;

- gestão de custeio (sustentabilidade) - viabilização econômica e financeira para garantir a manutenção e atualização dos serviços locais; 
c conteúdo - oferta de conteúdos locais, serviços e sistemas de informação em nosso idioma, democratização de toda informação legalmente pública e facilidade para produção e disseminação de conteúdo local.

Atualmente, existem muitas experiências de telecentros em curso, em diferentes níveis e, praticamente, em todo o mundo. São experiências de várias naturezas, patrocinadas por empresas privadas, fomentadas por ações governamentais no âmbito federal, estadual ou municipal, por ações de organizações nãogovernamentais (ONGs), instituições de ajuda internacionais e iniciativas do meio acadêmico, entre outras.

Para os estudiosos de telecentros, a sua configuração depende muito dos objetivos, da localização, das necessidades e da disponibilidade de recursos de cada iniciativa e de cada país, entre outros fatores. Essas características podem variar de país para país, dentro de uma mesma região, e até na mesma cidade.

O quadro a seguir permite identificar as diferenças e semelhanças existentes nos vários tipos de telecentros.

\section{Quadro 1}

\section{Tipos de telecentros}

\begin{tabular}{|c|c|c|}
\hline TIPO & SERVIÇOS & GESTÃO \\
\hline Comercial & $\begin{array}{l}\text { Os mais básicos oferecem acesso à } \\
\text { Internet e impressão de documentos. } \\
\text { Quando possuem cafeteria e bar, são } \\
\text { chamados de cybercafés. }\end{array}$ & Empresa Privada \\
\hline Franquia & $\begin{array}{l}\text { Oferece serviços de maior qualidade: } \\
\text { conexão mais rápida, melhor ambiente e } \\
\text { mais comodidade. }\end{array}$ & Empresa Privada \\
\hline ONG & $\begin{array}{l}\text { Observa-se uma grande variedade } \\
\text { de serviços oferecidos: dependendo } \\
\text { da instituição promotora, pode } \\
\text { oferecer acesso à Internet, cursos de } \\
\text { informática e realização de atividades de } \\
\text { desenvolvimento da comunidade. }\end{array}$ & $\begin{array}{l}\text { Organizações não } \\
\text { governamentais. } \\
\text { (dependem de doações } \\
\text { e alianças com } \\
\text { empresas privadas para } \\
\text { computadores e licenças } \\
\text { de software) }\end{array}$ \\
\hline Universitário & $\begin{array}{l}\text { Disponibilização de laboratório de } \\
\text { informática para os estudantes e público } \\
\text { em geral, possibilitando cursos de } \\
\text { computação e apoio técnico. }\end{array}$ & Universidades \\
\hline Escolar & $\begin{array}{l}\text { A escola abre as portas para a } \\
\text { comunidade em horário fora de aula. Os } \\
\text { serviços são variados (Internet, e-mail, } \\
\text { preparação de conteúdo). }\end{array}$ & Escolas \\
\hline Municipal & $\begin{array}{l}\text { Em princípio, oferece uma variedade de } \\
\text { serviços (públicos e privados). }\end{array}$ & $\begin{array}{l}\text { Município, em aliança } \\
\text { com outros órgãos e } \\
\text { empresas privadas } \\
\end{array}$ \\
\hline Polivalente & $\begin{array}{l}\text { Rural: acesso à Internet, correio } \\
\text { eletrônico e serviços agregados como } \\
\text { cabine telefônica, venda de material de } \\
\text { trabalho e papelaria, café e curso de } \\
\text { capacitação. } \\
\text { Centros de serviços e de cidadania (SAC). } \\
\text { Na Bahia e em outros estados do Brasil. } \\
\text { Oferecem serviços públicos. }\end{array}$ & $\begin{array}{l}\text { Junta administrativa, } \\
\text { provedores de serviços } \\
\text { e membros da } \\
\text { comunidade. } \\
\text { Governo Estatal }\end{array}$ \\
\hline
\end{tabular}

Fonte: Proenza, Bastida-Bush; Montero (2001)
No Brasil, o primeiro telecentro foi inaugurado em outubro de 1992, pelo governo federal, em Brusque, Santa Catarina, sendo o primeiro da América Latina (DARELLI, 2002). Segundo mapeamento realizado pelo Ibict (2007), existem mais de 16 mil telecentros em todo território nacional.

Figura 1

\section{Telecentros existentes no Brasil por estado}

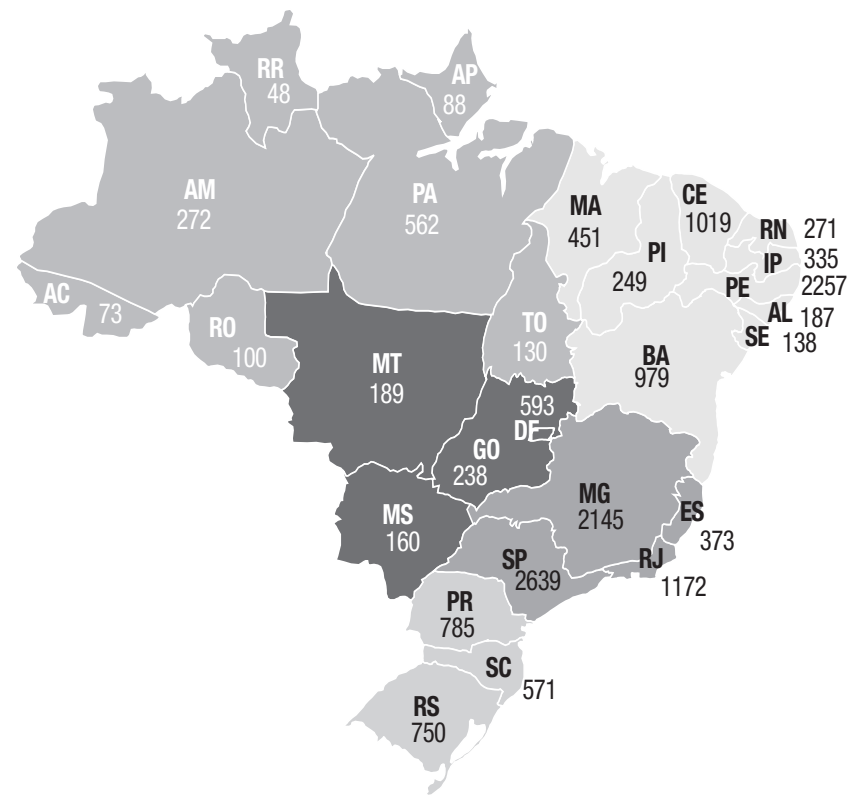

Fonte: Ibict (2007); pesquisa da autora Dulce Paradella.

Essas são iniciativas com características próprias; daí falarse em uma tipologia para os telecentros. Pela especificidade cultural e econômica do país, há controvérsia a respeito do cumprimento do papel social dos telecentros brasileiros. Analisando a situação, Silveira $(2005$, p.40) concorda que a criação de telecentros é uma estratégia viável na construção da cidadania, principalmente nas áreas de maior carência social. Para o autor, "[...] estar conectado às redes de informação e dominar tecnologias estratégicas pode fazer a diferença na construção de uma sociedade com qualidade de vida [...]"; porém, "o grande desafio é enfrentar a herança do analfabetismo funcional ao mesmo tempo que combatemos o apartheid tecnológico". Segundo o autor, "alegar que primeiro se erradica um, para depois enfrentar o outro, é um erro primário" (SILVEIRA, 2005, p.42). Dessa forma, estaríamos aumentando o distanciamento da sociedade da informação, que alimenta a exclusão e que impede que a nossa sociedade se prepare para os desafios do mercado de trabalho e da inserção competitiva no atual cenário mundial.

Oestman e Dymond (2001) apontam para outro desafio, o da subutilização e de insucesso de iniciativas em países em desenvolvimento:

- o analfabetismo, em geral, e o analfabetismo digital ${ }^{1}$, em particular; 
- o problema de linguagem causada pelo fato de que a maior parte do conteúdo da Internet está em inglês;

- a falta de consciência e cultura sobre o uso e os benefícios das TICs;

c o alto custo da conexão com a Internet, principalmente em regiões remotas.

Silveira (2005, p.36) é de opinião que a superação dos problemas que entravam a efetiva utilização dos telecentros pode advir da questão financeira: "[...] a nova Lei de informática pode tornar-se uma fonte de recursos para a inclusão digital no Brasil". Ela exige que, pelo menos, 5\% do faturamento bruto das empresas beneficiadas com o pagamento de menos tributos sejam aplicados em pesquisa e desenvolvimento. Para as empresas de informática, esse recurso poderá ser utilizado na construção de telecentros.

Mas sabe-se que não é esse o grande entrave. A ausência da democratização da informação advém do analfabetismo da população, da não-democratização da informática e da falta de recurso humano capacitado a oferecer aos usuários da informação melhores oportunidades de lidar com a informação, dentre outras questões.

Vê-se a complexidade que envolve a questão. Os entraves são vários. Vejam as inúmeras tentativas de transformar a experiência das bibliotecas públicas em um espaço democrático na trajetória histórica dos ambientes informacionais. Alguns desses entraves encontram-se na formação cultural, no sistema educacional, na descontinuidade de ações, na dificuldade de consensos e variadas áreas de conflito (técnicas e políticas), na falta de mão-de-obra qualificada, além daqueles relacionados à ausência de planejamentos, de análises mais acuradas e de estudos de necessidades informacionais das comunidades.

As propostas para se evitar a não-concretização dos objetivos inclusivos dos telecentros são muitas e, provavelmente, as apontadas nesse estudo possam ser fundamentais para alguma iniciativa. Quiçá pensar em sistemas locais, ao invés de sistemas macros, de difícil gerenciamento. A municipalização das bibliotecas e a criação de espaços comunitários poderiam proporcionar ações com co-responsabilidade, por meio grupos de sujeitos da comunidade com maior autonomia e considerando as peculiaridades do local. $O$ Estado não precisa fazer cronogramas comuns, com atividades itinerantes, mas a biblioteca pública, articulada com a escolar e/ou outros ambientes de mediação, pode tomar para si as iniciativas, desde que com o devido respaldo estrutural e o devido respeito ao trabalho do profissional da informação. As secretarias municipais costumam separar cultura e educação, embora não haja cisão entre as mesmas. Ambas são espaços de mediação da informação complementares. Assim, os telecentros poderiam dar aporte às ações conjuntas entre escolas, bibliotecas públicas e escolares, laboratórios de informática e outros ambientes informacionais e culturais.
É possível alcançar resultados positivos, aproveitando-se também do espaço telecentro para outras atividades, como, por exemplo, a realização de cursos e oficinas diversas, como a de jornalismo comunitário ou outras, com o objetivo de socialização da informação criada pela própria comunidade. A questão cultural e econômica do Brasil, no entanto, deve ser considerada em toda e qualquer análise sobre o panorama dos telecentros.

Ainda que muitos desafios se apresentem, soluções também são propostas. De qualquer maneira, a "infoinclusão", por meio de telecentros de uso comunitário e das bibliotecas públicas, trabalhando de forma mais articulada com os ambientes mediadores da comunidade, torna-se uma alternativa atraente em nosso país.

Difícil, sim, mas acostumados aos saltos culturais, comunicacionais e tecnológicos, os brasileiros podem ter, nesse contexto, grandes chances de ampliar - pelas ações conjuntas entre os ambientes informacionais - seu desenvolvimento, recuperando assim o atraso educacional. Assim ocorreu com a televisão. Criticada no início, acabou chegando às escolas, com programações pedagógicas acompanhadas e orientadas. Não se pode dizer que a utilização da televisão nas atividades pedagógicas promoveu enorme sucesso na educação. Da mesma maneira, não se pode prever, nem esperar, transformações a curto prazo. É possível administrar a informação, mas não se pode saber exatamente o que cada sujeito procura, ou mesmo como vai apropriar-se dessa informação e utilizá-la.

Ressalta-se que ainda existe uma carência de estudos sobre a realidade da exclusão digital no Brasil. O recente mapeamento realizado pelo Ibict, divulgado em maio de 2007, foi o primeiro estudo quantitativo abrangendo todo o país. $\mathrm{O}$ mapeamento oferece dados quantitativos, mas pesquisas acadêmicas têm apontado para aspectos qualitativos (JAMBEIRO; SILVA; BORGES, 2007). Está se analisando a melhoria de qualidade da educação e do acesso à informação. O próprio governo também já entende que o mais importante é ir além da distribuição de equipamentos. Tem-se consciência de que é preciso desenvolver novos conteúdos junto aos telecentros, aumentar a capacitação dos mediadores, acompanhar e avaliar os resultados alcançados, cotejando-os com os esperados.

\section{A DEMOCRATIZAÇÃO DA INFORMAÇÃO EM PROCESSO}

No cenário da sociedade da informação, as discussões, em seus variados níveis, políticos, econômicos, culturais e educacionais, que se ampliam em função das alterações, provocadas pelas TICs, incidem sobre os comportamentos culturais e sociais. Inclusão social via inclusão informacional, quer seja pelas bibliotecas públicas, pelos telecentros, ou pelas parcerias com outros ambientes de mediação da informação, é uma discussão 
efervescente. Vale ressaltar algumas questões relevantes: a infraestrutura, o apoio financeiro sem sentido, a manutenção, a atualização tecnológica necessária. Para o êxito de programas inclusivos, no entanto, outras questões apontam relevância e referem-se à capacitação, primeiramente dos mediadores, para que estes tenham competência para atuar junto aos usuários.

Educação informacional é como tem sido chamado o conjunto de habilidades para acessar, usar, criticar, interpretar e apropriar-se, ou não, da informação. As escolas podem inserir em seus currículos um tempo para o desenvolvimento dessas habilidades, além do acesso somente ao tecnológico, ou seja, aos computadores. Daí reiterar-se a necessidade de o mediador-formador não somente ser conhecedor das fontes e canais de informação, mas também ter uma visão pedagógica, comunicativa e gerencial sobre a informação. Também é fundamental perceber a importância de ampliar e interagir mais extensamente com outros ambientes informacionais, em dimensão mais local.

Espaços informacionais, tradicionais ou novos, são ambivalentes, ao mesmo tempo que são grandes oportunidades de desenvolvimento social. Apresentam-se também como grandes desafios. Mas essa é a trajetória do homem e da cultura, e nesse diálogo é impossível intervir ou prever resultados. O que não se pode praticar é a omissão. São de responsabilidade da sociedade o dever e o direito de exercer a cidadania. Não se pode deixar de provocar o uso e o acesso à informação, de ofertar o que é produção coletiva. A ética humana insere-se no plano do bem-estar social, da liberdade para participar do coletivo e do desenvolvimento humano.

O que se pode dizer é que, de fato, a biblioteca pública pode reduzir as diferenças entre os que acessam e usam a informação e os que estão alijados desse processo. As tecnologias de informação podem melhorar, em muito, a condição das bibliotecas, em vários sentidos. Não apenas no processamento da informação, mas principalmente na sua recuperação e, com isso, dar maior relevância social aos seus serviços. Este é seu papel no processo da inclusão social: tornar a informação democratizada. É bem como diz Cunha (2003):

A sociedade da informação, nos diferentes espaços geográficos em que vem sendo concebida, atribui à biblioteca pública a missão especial de assegurar a democratização do acesso em rede, a oferta de produtos e serviços de qualidade que contribuam para diminuir as desigualdades sociais e estimular os usuários a utilizar a Internet como instrumento de ampliação de conhecimento e convivência.
Os telecentros, igualmente, podem ser instrumentos poderosos para o desenvolvimento social, via inclusão digital. Entretanto, isso não será possível sem que se revertam suas ações em favor de uma comunidade, o que colaboraria para reduzir o déficit educacional que o país tem com sua população. É necessário que, aos ambientes informacionais, sejam agregados conteúdos de informação mais amplos, assim como maior diversidade de suportes, para que se constituam espaços multi e intersemióticos, e que ações e serviços estejam mais próximas das necessidades reais dos usuários, mais particularmente, dos usuários em potencial. Além disso, a educação informacional deve ser adequada aos níveis de educação pretendidos e garantir melhores níveis informacionais, isto é, maiores condições para o uso efetivo das redes.

Muitos desafios apresentam-se, não apenas os ligados a questões técnicas e conceituais, mas também os que concernem a questões sociais, legais e éticas. É o caso dos aspectos legais da propriedade intelectual do documento disponibilizado em rede, que necessitam um repensar. É o caso, também, do acesso às redes pelos portadores de necessidades especiais $\mathrm{e}$ idosos - camadas especiais da sociedade, excluídas sob nova modalidade de exclusão: a exclusão simbólica. A acessibilidade à informação - impressa, visual auditiva, manuscrita, digital etc. - deve contemplar não só capacidades técnicas e conceituais, mas igualmente o exercício da cidadania e da construção de uma sociedade inclusiva.

A sustentabilidade é outro aspecto a ser perseguido Os modelos de bibliotecas públicas e de telecentros devem estar associados a um projeto de longo prazo, capaz de conectar os anseios dos grupos e comunidades atendidas com o potencial de alavancagem das TICs. Para que se possa diminuir a quantidade dos "informacionalmente excluídos", é fundamental aumentar a quantidade e a qualidade das bibliotecas públicas e dos telecentros. Isso pode ser possível mediante ações governamentais mais eficientes, iniciativas comunitáriase e de parcerias com ONGs, empresas privadas e organismos internacionais como a Unesco.

Artigo submetido em 11/11/2007 e aceito para publicação em 07/01/2008. 


\section{REFERÊNCIAS}

ACESSO à informação promove inclusão social. Consciência: revista eletrônica de jornalismo científico, SBPC, n.45, jul. 2003. Disponível em: < http://www.comciencia.br/reportagens/framereport.htm > Acesso em: 12 jul. 2006.

AFONSO, Carlos Alberto. Internet no Brasil: o acesso para todos é possível? Rio de Janeiro: [s.n.], 2000. (Policy Paper, n. 26). Disponível em: < http://www.fes.org.br/publicacoes.htm> Acesso em: 21 abr. 2007.

AQUINO, Miriam de Albuquerque. Metamorfose da Cultura: do impresso ao digital, criando novos formatos e papéis em ambientes de informação. Ciência da Informação. Brasília, v.33, n.2, p.7-14, mai-ago. 2004.

BARRETO, Angela Maria. Memória e Leitura: as categorias da produção de sentidos. Salvador, EDUFBA, 2006.

BORGES, Jussara; SILVA, Helena P. Informação e mudança: estudo da efetividade dos programas de inclusão digital em Salvador-Bahia. In: CONGRESSO BRASILEIRO DE CIENCIAS DA COMUNICAÇÃO, 2005, Rio de Janeiro. Anais... São Paulo: Intercom, 2005. CD-ROM.

BRASIL. Comitê Gestor da Internet no Brasil. Pesquisa sobre o uso das tecnologias da informação e da comunicação no Brasil 2005; TIC domicílios e TIC empresas. Brasília, 2006. 306p. Disponível em: $<$ http://www.nic.br/indicadores/indicadores.pdf > . Acesso em: 03 maio 2007.

CAMPAL, M. F. Garcia. Los telecentros y las bibliotecas públicas: nuevas alianzas para la sociedad de la información. In: FORO BIBLIOTECA Y SOCIEDAD EXPERIENCIAS DE INNOVACIÓN Y MEJORA, 2004, Murcia, ES. Disponível em: < http://www. anabad.org/encuentros/foroexperiencias/index@b=3\&c=19. html>. Acesso em: 5 jun. 2007.

CUNHA, Vanda Angélica da. A biblioteca pública no cenário da sociedade da informação. Biblos, anol4, n.15, abr jun, 2003. p.6776

DARELLI, Lúcio Eduardo. Telecentro como instrumento de inclusão digital para o e-gov brasileiro. 2002. 124p. (Dissertação (Mestrado) Escola de Engenharia de Produção e Sistemas, Universidade Federal de Santa Catarina.

FERREIRA, F; SPENCE, J; STRAUBHAAR, J. Comparando iniciativas governamentais e não-governamentais de inclusão digital nos EUA e no Brasil. In: JAMBEIRO, O; SILVA, H; BORGES, J. (Org). Cidades contemporâneas e políticas de informação e comunicações. Salvador, EDUFBA, 2007. p.237-257.

FRAGO, Antonio Vinao. O discurso bibliotecário sobre a leitura. Pátio: revista Pedagógica, Porto Alegre, n.14, ago. set., 2000.

GÓMEZ, R; HUNT, P; LAMOUREUX, E. Telecentros en la mira: cómo pueden contribuir al desarrollo social? Revista latinoamericana de comunicación: Chasqui, Quito, Ecuador: Centro Internacional de Estudios Superiores de Comunicación para América Latina (CIESPAL), n.67, jun. 1999.

IBICT. Mapa de inclusão digital. 2007. Disponível em: < http:// inclu $\sim$ sao.ibict.br $>$. Acesso em: 20 jun. 2007.
INFOTICS: lista de correo sobre tecnologías de la información y de la comunicación, n. 9, 2004. Disponível em: <http://www.campus-emexico.edu.mx/campus2/infitics/index09.htm $>$. Acesso em 6 jun. 2007

JAMBEIRO, O.; SILVA, H. P. da; BORGES, Jussara. Cidades contemporâneas e políticas de informação e Comunicação. Bahia: EDFUBA, 2007. 39 p.

LEVACOV, Marília. Bibliotecas Vituais:@evolução? Ciência da Informação, Brasília, v.26, n.2, mai ago. 1997

MARCHIORI, Patrícia Zeni. Ciberteca ou Biblioteca Virtual: uma perspectiva de gerenciamento de recursos de informação. Ciência da Informação, Brasília, v.26, n.2,p.114-124, maio/ago.1997.

O'NEIL, Dara. Assessing community informatics: a review of methodological approaches for evaluating community networks and community technology centers. Internet Research: Electronic Networking Applications and Policy, v. 12, n. 1, p. 76-102, 2002. Disponível em:

<http://www.emeraldinsight.com/1066-2243.htm>. Acesso em: 23 maio

2007.

OBRA AGUILA, A.R.. del; CÂMARA, Bruque S.; MELLENDEZ Padilla A. A analysis of teleworking. centres in Spain. Facilities. v.20, n.11-12, p.394-3999, 2002. Disponível em http://emeraldinsight. com\0263-2772-htm. Acesso em 06 jun.,2007

OESTMAN, S.; DYMOND, A.C. Telecentres: experiences, lessons and trends. In: LATCHEM, C.; WALKER, D. Perpectives on distance education: telecentre: case studies and studies and key issues. Vancouver: The Commonwealth of Learning, 2001. p. 1-16.

PARADELLA, Dulce. Acesso e uso da informação em telecentros: um estudo em comunidades carentes de Salvador. BA. 2008. Dissertação de Mestrado em Ciência da Informação) - Instituto de Ciência da Informação. Universidade Federal da Bahia, Salvador, 2008.

PIMENTEL, Maria das Graças. Biblioteca pública e Inclusão digital: desafios e perspectivas na era da informação, Brasília, UNB, 2006 (Dissertação de Mestrado).

PROENZA, F; BATIDAS-BUSH, R; MONTEIRO, G. Telecentros para el dessarollo socioeconômico y rural en América Latina y el Caribe. Washington, D.C. $\{s n\}, 2001$. Disponível em http: WWW.IADB. ORG;REGIONSNTELECENTROS INDEX HTM. Acesso em 10 de abr., 2007.

SILVEIRA, Sérgio Amadeu. Exclusão digital: a miséria na era da informação. São Paulo: Fundação Perseu Abramo, 2005. 48p.

SOUSA, Maria Isabel de J. Olhares entrecruzados: práticas da leitura na sala de aula e na biblioteca do Centro Educacional Carneiro Ribeiro. 2007. 256f. Tese (Doutorado em Educação)-Faculdade de Educação, Universidade Federal da Bahia, Salvador, 2007.

SUAIDEN, Emir José. Biblioteca pública brasileira: desempenho e perspectivas. São Paulo, Lisa, INL, 1980.

SUPERINTENDÊNCIA DE ESTUDOS ECONÔMICOS E SOCIAIS DA BAHIA. Regiões econômicas do estado da Bahia. 
Salvador, 2007. Disponível em: <http://sei.ba.gov.br/publicacoes/ publicacoes-sei/bahia-dados>. Acesso em: 23 jun. 2007.

TAKAHASHI, Tadao (Org.). Sociedade da informação no Brasil: livro verde. Brasília: Ministério da Ciência e Tecnologia, 2000. $203 \mathrm{p}$.

UNESCO. Manifiesto de la Unesco sobre la biblioteca pública. Paris: UNESCO, 1994.

UNESCO TELECENTRO. 